\title{
The effect of body condition and level of feeding on the partition of internal fat and the size of the digestive tract in adult Churra ewes
}

\author{
P. Frutos ${ }^{1}$, A. R. Mantecón', J. S. González ${ }^{2}$ \\ ${ }^{1}$ Estación Agrícola Experimental, Consejo Superior de Investigaciones Cientificas, Apartado 788, 24080 León, Spain \\ 2Departamento de Producción Animal, Universidad de León, 24071 León, Spain
}

\section{Introduction}

Most sheep production systems under arid or semiarid conditions are dependent on the ability of the animals to retain and mobilize body fat and on their capacity to consume large amounts of low quality forages.

The aim of this paper is to study the effect of level of intake and body condition score on the proportions of the components of the digestive tract and different internal fat depots in the Churra ewe, a breed which is adaptated to semi-arid conditions, in the centralnorth area of Spain.

\section{Material and methods}

Thirty-six mature Churra ewes were allocated to nine treatments, according to a $3 \times 3$ factorial design represented by three levels of intake of a low quality hay (high: ad libitum, medium: 0.8 of ad libitum and low: 0.6 of ad libitum) and three body condition scores (BCS) (good: >3, medium: between 2 and 3 and poor: $<2$ ).

All animals were individually penned throughout, food offered and refused was weighed daily and live weight (LW) was recorded twice weekly. After a period of 2 weeks on the experimental treatments all ewes were slaughtered and the LW and the full and empty components of the digestive tract after the removal of fat and the internal fat depots (perirenal, omental and mesenteric) were weighed.

\section{Results and discussion}

The $L W$ at the beginning of the experiment were 44.9 , 47.0 and $50.7 \mathrm{~kg}$ and the animals on the high, medium and low levels of intake lost 56, 78 and $126 \mathrm{~g} / \mathrm{kg}$ initial LW respectively. Corresponding values for the groups with good, medium and poor BCS were 52.5, 49.1, $40.6 \mathrm{~kg}$ and $88,106,72 \mathrm{~g} / \mathrm{kg}$ respectively.
Dry-matter intake was significantly $(P<0.001)$ different among the BCS categories and the values were $12.5,10.7$ and 15.2 (s.e. $=0.58$ ) $\mathrm{g} / \mathrm{kg} \mathrm{LW}$ per day for good, medium and poor BCS respectively. This effect was associated with statistically significant changes in proportions of the digestive tract and its contents, with higher values when the BCS decreased (see Table 1).

The components of the digestive tract as a proportion of empty body weight (EBW) increased significantly affected by level of intake, except for the proportion of the omasum and the large intestine (see Table 1).

The total internal fat (TIF) and its components as a proportion of EBW increased significantly when the level of intake decreased, as a consequence of the variation in $L W$, except for the mesenteric fat which was not affected. The proportions of perirenal fat and omental fat in the TIF were not affected by intake, but the proportion of mesenteric fat in the TIF showed a lower value for the low level of intake (see Table 2).

There was a significant direct relationship between different internal depots and BCS. The animals with poor BCS had a lower value of perirenal fat and a higher value of mesenteric fat as proportions of TIF. The omental fat as a proportion of TIF was not affected by BCS (see Table 2).

\section{Conclusions}

Both the level of intake and BCS had an effect on the components of the digestive tract as a proportion of EBW. These factors affect the re-partitioning of internal fat depots in Churra ewes. Both factors are hence of nutritional significance in grazing systems in arid regions, which impose wide fluctuations in intake and condition of ewes.

\section{Acknowledgement}

Proyecto CICYT GAN90-0906. 
Table I Empty body weight (EBW, $\mathrm{kg}$ ) and components of the digestive tract $(\mathrm{g} / \mathrm{kg}$ EBW)

\begin{tabular}{|c|c|c|c|c|c|c|c|c|c|}
\hline & \multicolumn{3}{|c|}{ Level of intake } & \multirow[b]{2}{*}{ Significance } & \multicolumn{3}{|c|}{ Body condition } & \multirow[b]{2}{*}{ Significance } & \multirow[b]{2}{*}{ s.e. } \\
\hline & Ad libitum & 0.8 & 0.6 & & $>3$ & $2-3$ & $<2$ & & \\
\hline Hay intake (g/day) & 737 & 576 & 473 & & 655 & 520 & 600 & & \\
\hline $\begin{array}{l}\text { EBW } \\
\text { Total digestive tract }\end{array}$ & & 0.85 \\
\hline Empty & 83 & 77 & 71 & $* *$ & 64 & 77 & 90 & $* * *$ & 2.5 \\
\hline Contents & 302 & 256 & 231 & $* * *$ & 202 & 257 & 333 & $* * *$ & $12 \cdot 1$ \\
\hline \multicolumn{10}{|l|}{ Reticulum-rumen } \\
\hline Empty & 33 & 32 & 30 & 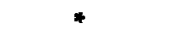 & 27 & 32 & 36 & $* * *$ & 0.8 \\
\hline Contents & 223 & 185 & 169 & $*$ & 144 & 191 & 244 & $* * *$ & 12.9 \\
\hline \multicolumn{10}{|l|}{ Omasum } \\
\hline Empty & $4 \cdot 7$ & $4 \cdot 3$ & $3 \cdot 8$ & & 3.6 & $4 \cdot 1$ & $5 \cdot 1$ & $*$ & 0.30 \\
\hline Contents & $7 \cdot 1$ & 7.2 & $5 \cdot 4$ & & $6 \cdot 2$ & $6 \cdot 0$ & 7.4 & & 0.70 \\
\hline \multicolumn{10}{|l|}{ Abomasum } \\
\hline Empty & 8.5 & $6 \cdot 8$ & $6 \cdot 2$ & $* *$ & $6 \cdot 0$ & $7 \cdot 6$ & 7.9 & $*$ & 0.45 \\
\hline Contents & $6 \cdot 0$ & $6 \cdot 5$ & $8 \cdot 1$ & & 6.2 & 6.1 & 8.6 & & $1 \cdot 14$ \\
\hline \multicolumn{10}{|l|}{ Small intestine } \\
\hline Empty & 16.4 & 13.7 & $12 \cdot 6$ & $* * *$ & $11 \cdot 7$ & $13 \cdot 4$ & $17 \cdot 6$ & $* * *$ & 0.55 \\
\hline Contents & $24 \cdot 5$ & 20.2 & 16.0 & $* *$ & $15 \cdot 4$ & 18.9 & $26 \cdot 6$ & $* * *$ & 1.55 \\
\hline \multicolumn{10}{|l|}{ Large intestine } \\
\hline Empty & $18 \cdot 6$ & $18 \cdot 8$ & $15 \cdot 7$ & & $14 \cdot 3$ & $17 \cdot 7$ & $21 \cdot 3$ & $* *$ & 1.39 \\
\hline Contents & $26 \cdot 4$ & 23.7 & 21.5 & & 18.9 & $21 \cdot 4$ & 31.7 & ** & 2.80 \\
\hline \multicolumn{10}{|l|}{ Caecum } \\
\hline Empty & $2 \cdot 3$ & $2 \cdot 0$ & 1.7 & $*$ & 1.7 & $2 \cdot 1$ & $2 \cdot 3$ & $*$ & 1.21 \\
\hline Contents & $15 \cdot 3$ & $14 \cdot 1$ & 11.0 & & 10.9 & $14 \cdot 3$ & $15 \cdot 1$ & & 1.47 \\
\hline
\end{tabular}

Table 2 Total internal fat (TIF) and its components

\begin{tabular}{|c|c|c|c|c|c|c|c|c|c|}
\hline & \multicolumn{3}{|c|}{ Level of intake } & \multirow[b]{2}{*}{ Significance } & \multicolumn{3}{|c|}{ Body condition } & \multirow[b]{2}{*}{ Significance } & \multirow[b]{2}{*}{ s.e. } \\
\hline & Ad libitum & 0.8 & 0.6 & & $>\mathbf{3}$ & $2-3$ & $<2$ & & \\
\hline $\begin{array}{l}\text { TIF (g/kg EBW) } \\
\text { Perirenal fat }\end{array}$ & 52.2 & $57 \cdot 1$ & $76 \cdot 1$ & $* *$ & 80.6 & $64 \cdot 9$ & $38 \cdot 7$ & $* * *$ & $5 \cdot 30$ \\
\hline $\begin{array}{l}\mathrm{g} / \mathrm{kg} \text { EBW } \\
\mathrm{g} / \mathrm{kg} \text { TIF }\end{array}$ & $\begin{array}{r}12 \cdot 1 \\
226 \cdot 0\end{array}$ & $\begin{array}{r}12.9 \\
225 \cdot 5\end{array}$ & $\begin{array}{r}18.0 \\
234.9\end{array}$ & $*$ & $\begin{array}{r}19.8 \\
253.6\end{array}$ & $\begin{array}{r}15 \cdot 8 \\
248.9\end{array}$ & $\begin{array}{r}6.9 \\
179.9\end{array}$ & $* * 4$ & $\begin{array}{r}1.33 \\
19.35\end{array}$ \\
\hline $\begin{array}{c}\text { Omental fat } \\
\text { g/kg EBW } \\
\text { g/kg TIF }\end{array}$ & $\begin{array}{r}21 \cdot 6 \\
414 \cdot 9\end{array}$ & $\begin{array}{r}25.8 \\
413.7\end{array}$ & $\begin{array}{r}37.4 \\
482.9\end{array}$ & $*$ & $\begin{array}{r}38 \cdot 4 \\
454 \cdot 6\end{array}$ & $\begin{array}{r}28.9 \\
432.5\end{array}$ & $\begin{array}{r}17 \cdot 1 \\
425 \cdot 3\end{array}$ & $*$ & $\begin{array}{r}3.89 \\
31.76\end{array}$ \\
\hline $\begin{array}{c}\text { Mesenteric fat } \\
\text { g/kg EBW } \\
\text { g/kg TIF }\end{array}$ & $\begin{array}{r}18.5 \\
359.1\end{array}$ & $\begin{array}{r}18 \cdot 4 \\
360 \cdot 8\end{array}$ & $\begin{array}{r}20 \cdot 6 \\
282 \cdot 3\end{array}$ & $*$ & $\begin{array}{r}22 \cdot 3 \\
291 \cdot 8\end{array}$ & $\begin{array}{r}20 \cdot 2 \\
318 \cdot 6\end{array}$ & $\begin{array}{r}14 \cdot 7 \\
394 \cdot 7\end{array}$ & * & $\begin{array}{r}1.76 \\
24 \cdot 38\end{array}$ \\
\hline
\end{tabular}

